International Journal of Engineering \& Technology, $7(2.24)(2018) 208-213$
International Journal of Engineering \& Technology
SPC
Website: www.sciencepubco.com/index.php/IJET
Research paper

\title{
A single stage ZVS Power factor correction converter
}

\author{
G. Ravivarman ${ }^{1}$, S. Poorani ${ }^{2}$ \\ ${ }^{1}$ Assistant professor, Department of Electrical and Electronics, JCT College of Engineering and Technology, Coimbatore \\ ${ }^{2}$ Professor, Department of Electrical and Electronics, Karpagam Academy of Higher Education. Coimbatore, Tamilnadu, India. \\ *Corresponding Author Email: ravivarmanme@gmail.com
}

\begin{abstract}
The aspects with respect to control strategies power factor correction (PFC) converter are examined. Research effort in focus to minimized switching stress for improving better efficiency in power rating is $500 \mathrm{~W} / 48 \mathrm{~V}$, is achieved by using soft switching. In this suggested converter and switching scheme ZVS voltage stress is shaped. Added to this power loss is minimized. A 500W/48V prototype is proposed to serve the concept proof, which exhibits $92.69 \%$ peak efficiency at low input line voltage.
\end{abstract}

Keywords: Power factor correction, Zero voltage switching, Zero current switching, Total harmonics Distortion, Soft switching, Single Stage converter.

\section{Introduction}

In accordance with IEC 1000-3-2, required to achieved with power factor high and very low THD at power conversion of ac/dc for the purpose of full usage of the lines transmission and for improved grid nature, Passive electronic components are those that don't have the ability to control current by means of another electrical signal, but Active electronic components are those that can control the flow of current. So we conclude that active component better than passive component. In passive power factor correction method, the inductive and capacitive filter is used between the AC supply and diode rectifier of AC/DC converter is a very finest way to achieved power factor correction but the main drawback of this is very heavy and bulky so it's applicable only for low power rating like less than $25 \mathrm{~W}$.

To work at high frequency, the circuit size to be decreased. The high-frequency double -stage functioning PFC converters have been put-forth [3] and [5] . In the first stage ac/dc, the PFC converter is working with switching frequency in the tenth to several hundred $\mathrm{KHz}$ to tenths and vice versa, to acquire proper input current which is near to sinusoidal waveform. In the second stage, the galvanic isolation and output voltage regulation are provided by $\mathrm{dc} / \mathrm{dc}$ converter. Both stage controllers are totally independent of one another.

The Single-Stage ac/dc converter is the cost-effective one for the reduction in the number of switches [5]. In single stage the frontend PFC and dc/dc are working together as a unit. The capacitor or inductor is in between both the stage which acts an energy storage unit and gives up enough hold up time. A lot of PFC ac/dc are put forth, working in a discontinuous mode for effective PF control.

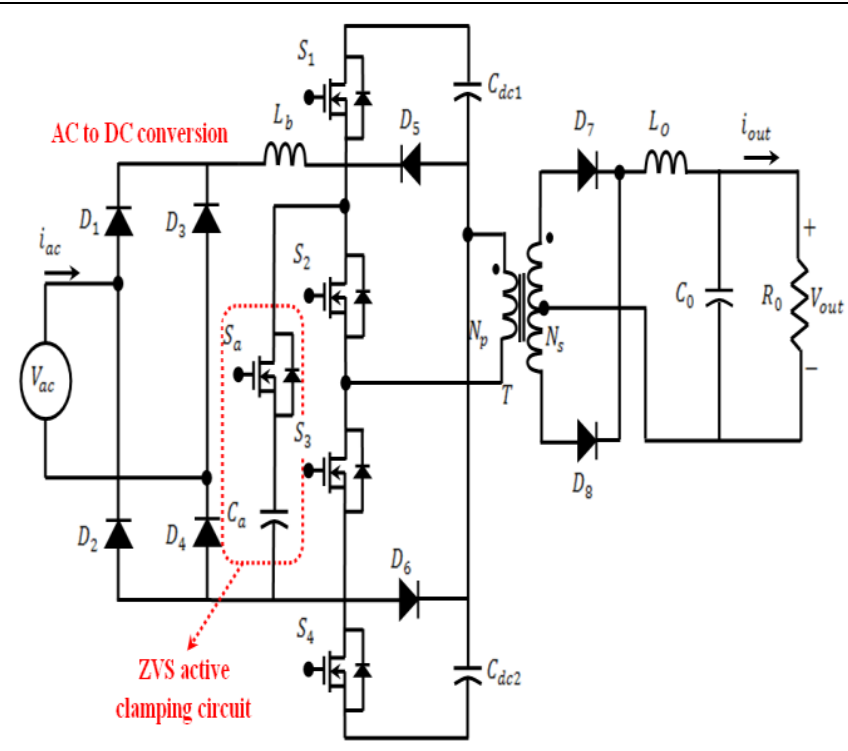

Fig. 1: Proposed ZVS single stage ac-dc converter

This study suggests not an old SSTC stand-alone ac-dc PFC converter which is achieved with completed working togetherness of double stages, where the switch is distributed between input current and output voltage as in Fig.1.The proposed converter gives the least components as three-level dc/dc converter, which will not need auxiliary circuit except a diode bridge and an inductor. This topology is cost efficient application for a high voltage dc-link.[6]-[11].

The two self -dependent algorithms are mingled together to achieve PFC and output regulation. In light load also the feature allows for lower ripple and less change input current. Added to this center two switches are in ON condition under zero current in discontinuous conduction mode operation and the top and lower switches are turned $\mathrm{ON}$ under zero volt, where the efficiency is raised up. Moreover, high rate $\mathrm{PF}$ can be accruing at high line voltage as a result of flexible dc-link voltage is organized. 
Switching transitions occur under the favorable conditions where device voltage current is zero. The problem is due to the absent of ZVS in switching losses, device stress, thermal management and electromagnetic interference due to high $\mathrm{di} / \mathrm{dt}$ and $\mathrm{dv} / \mathrm{dt}$, energy losses in stray inductor and capacitor. In order to overcome the absence of ZVS an active soft switching (ZVS) is implemented. It helps in reducing switching loss and switching stress with a possible low EMI. The Easier thermal management is for very high-frequency operation and also for a medium frequency at high power operation and also for a medium frequency at high power levels.[4]

The Zero voltage switching can be portrayed as, the power to the device is turned $\mathrm{ON}$ or OFF, only when the output voltage is zero volts. The voltage regulator can engage in soft switching with the help of ZVS, which help to avoid switching losses that are normally seen during conventional PWM operation [11] . On turning to soft switching, the voltage drops to zero instead of just minimum before the metal -oxide semiconductor field effect transistors are turned OFF or ON. This helps in eliminating losses. Another advantage with soft switching is, the waveform minimized electromagnetic interference.(EMI).

\section{Proposed Converter}

The proposed converter is a basic and fundamental of a boost PFC circuit and dc-dc three -level isolated converter. In general, an inductor and diode bridge are joined to the three-level isolated dcdc topology as shown in fig (1).Here, the inductor is charged when S2 and S3 are turned ON before getting ON soft switch Sa to avoid voltage stress in switches S2 and S3, Switches S2 and S4 of body diode is act as the boost diode of the PFC boost converter. Simultaneously, S1 -S4 are switched to supply voltage of Vdc/2,$\mathrm{Vdc} / 2$ and primary side of the transformer is a Zero voltage [8]. The switching of conventional three-level isolated $\mathrm{dc} / \mathrm{dc}$ converter is shown in fig 2 .

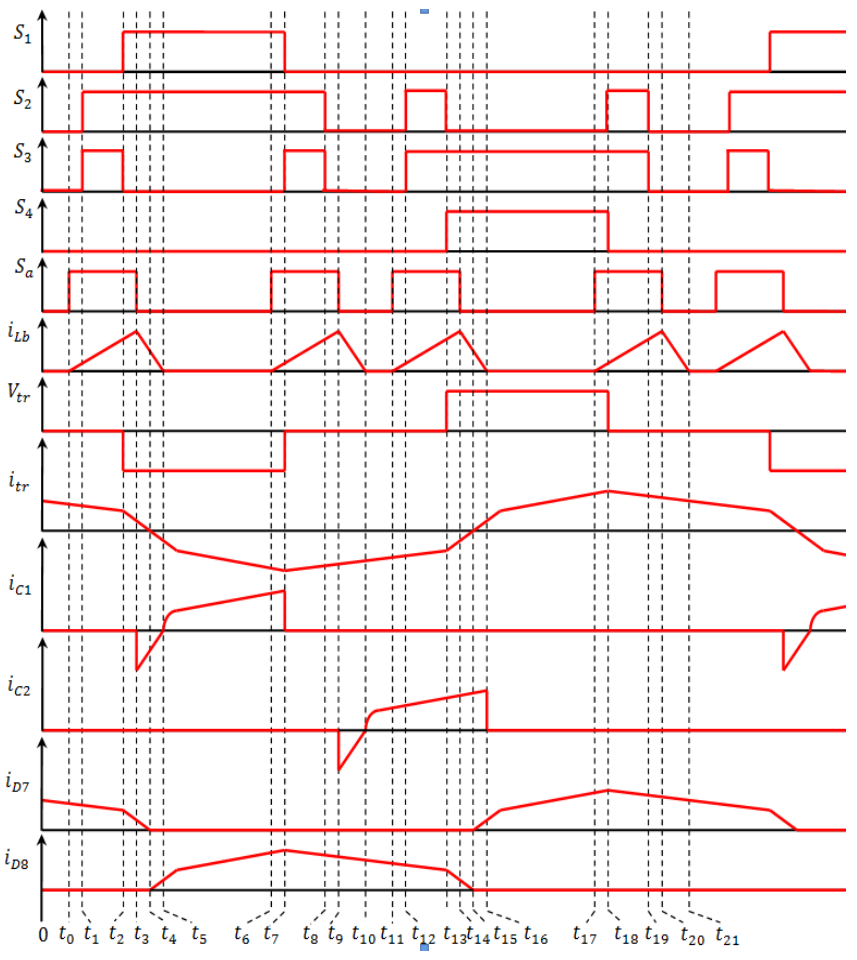

Fig. 2: Proposed switching scheme of conventional three-level isolated $\mathrm{dc} / \mathrm{dc}$ converter

In the conventional scheme, $\mathrm{S} 2$ and $\mathrm{S} 3$ switches are close to $50 \%$ duty ratio for smoothness in control and also confirmed that upper and lower switches are turned OFF at the same time this causes short-circuit through dc-link.

In switching scheme of the converter dc-dc the switches, S2-S3 switches are always higher than 0.5 for the overlap of two signal, input inductor current is discontinuous, $\mathrm{S} 1-\mathrm{S} 4$ is $\mathrm{ON}$ when $\mathrm{S} 2-\mathrm{S} 3$ is turned OFF.

The proposed switching scheme of conventional three level isolated dc-dc converter, in this time interval $\left(\mathrm{t}_{0}-\mathrm{t}_{1}\right)$, switch $\mathrm{Sa}$ is turned $\mathrm{ON}$ under zero voltage switching condition remaining switches $\mathrm{S} 1, \mathrm{~S} 2, \mathrm{~S} 3, \mathrm{~S} 4$ turn off as shown in fig (2) this operation for to avoid voltage stress in switches S2 and S3 by ON Sa switches before ON S2 and S3, at this time operation storage voltage in line inductor iLb increases and line voltage Vtr suddenly fall to zero and switching voltage from the previous stage are flow through soft switch Sa to negative terminal of supply voltage [10].

\section{Operation Mode}

In this time interval $\left(t_{0}-t_{1}\right), S_{a}$ is turned $O N$ under zero voltage switching condition, $i_{\mathrm{lb}}$ current discharge to negative terminal of supply voltage through $S_{a}$, primary side of a transformer create circulating path through switch $S_{3}$, forward bias $D_{6}$ and leakage fluk in secondary to the load by forward bias $\mathrm{D}_{7}$ at this time $\mathrm{D}_{8}$ is act as reverse bias as shown in fig (3a)

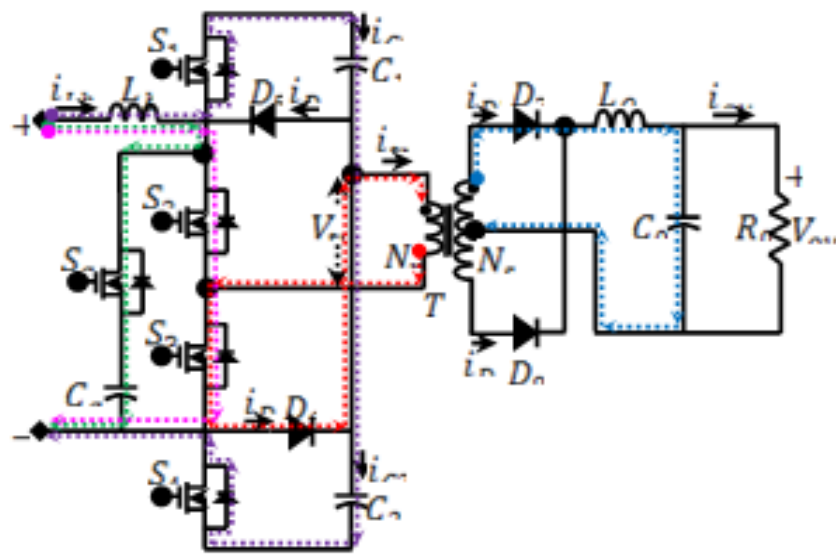

Fig. 3: (a) Equivalent circuit

In this interval $\left(t_{2}-t_{3}\right)$, switches $S_{1}, S_{2}, S_{a}$ is turned ON. In this state $D_{5}$ is reverse bias $i_{l b}$ current discharge $S_{a}$ through $C_{a}$, here circulating current in primary side of transformer through switch $S_{1}$ and $S_{2}$ and leakage flux in secondary by forward bias $D_{7}$ to load as shown in Fig (3b)

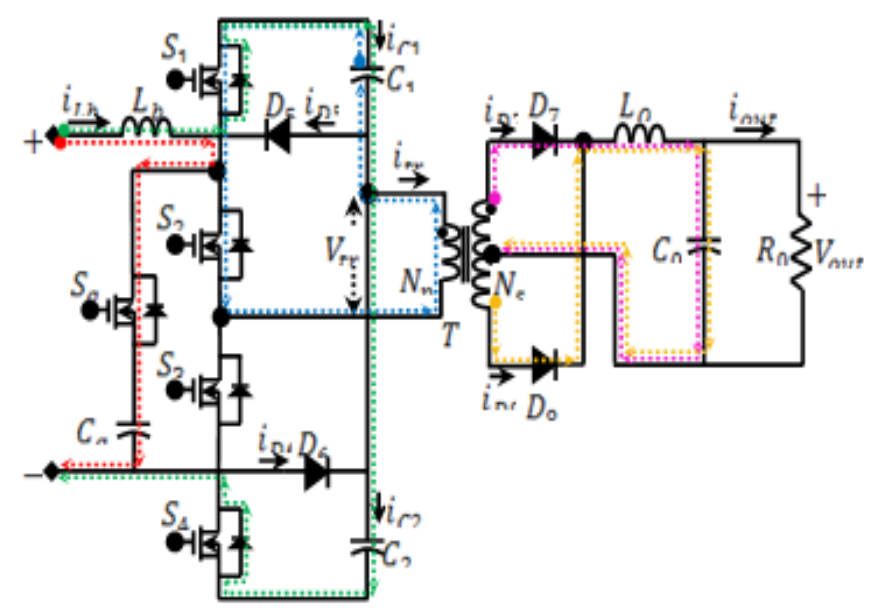

Fig. 3: (b) Equivalent circuit

In this Mode at time interval $\left(t_{3}-t_{4}\right)$, switches $S_{1}$ and $S_{2}$ turned ON. In this state Diode $\mathrm{D}_{5}$ and $\mathrm{D}_{6}$ are reverse bias so in primary side of transformer current circulating path through $\mathrm{S}_{1}$ source to 
drain to discharge capacitor voltage $\mathrm{C}_{1}$ and $\mathrm{C}_{2}$ to negative charge by switch $\mathrm{S}_{4}$ in secondary side leakage flux by forward bias diode $\mathrm{D}_{7}$ as shown in fig ( $\left.3 \mathrm{~b}\right)$.

In this time interval ( $\left.\mathrm{t}_{7}-\mathrm{t}_{8}\right)$,in this state $\mathrm{S}_{\mathrm{a}}$ is turned $\mathrm{ON}$ charge start to discharge through switches $S_{2}$ and $S_{3}$ to negative terminal Under these circumstances $D_{5}$ acts as forward bias primary side of the transformer produced circulating current through switch $S_{2}$ by the waveform as shown in fig (2) note that $\mathrm{V}_{\text {tr }}$ tends to zero flux leakage in secondary to load by forward bias diode $\mathrm{D}_{8}$ as shown in fig (3c).

In this interval ( $\left.t_{8}-t_{9}\right)$, in this state switch $S_{a}$ is turned circulating path in primary and secondary side is same as previous stage as shown in fig (3c)

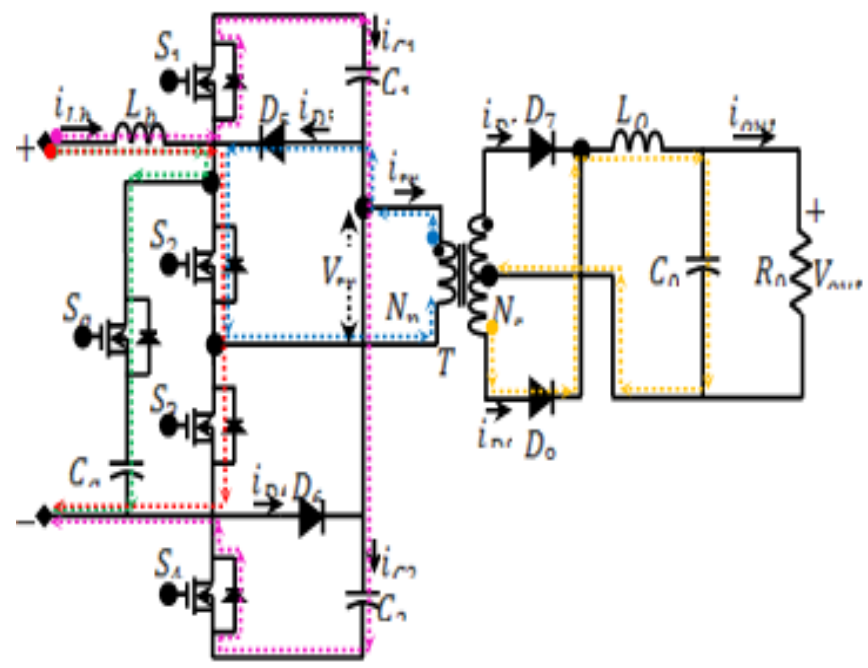

Fig. 3: (c) Equivalent circuit

In this time interval $\left(t_{13-}-t_{14}\right)$, in this state $S_{1}$ and $S_{2} O F F i_{1 b}$ current discharge to negative terminal of supply voltage through auxiliary switch $S_{a}$ current circulating path in primary transformer through $\mathrm{S}_{3}$ and $\mathrm{S}_{4}$ switches leakage flux in secondary through Forward bias diode $\mathrm{D}_{8}$ to load at this time $\mathrm{D}_{7}$ act as a reverse bias as shown in Fig 3(d).

In this time interval $\left(t_{15}-t_{16}\right)$, in this state $S_{3}$ and $S_{4}$ switches turned $\mathrm{ON}$ at this time leakage flux in secondary to the load through $\mathrm{D}_{7}$ as shown in fig 3(d)

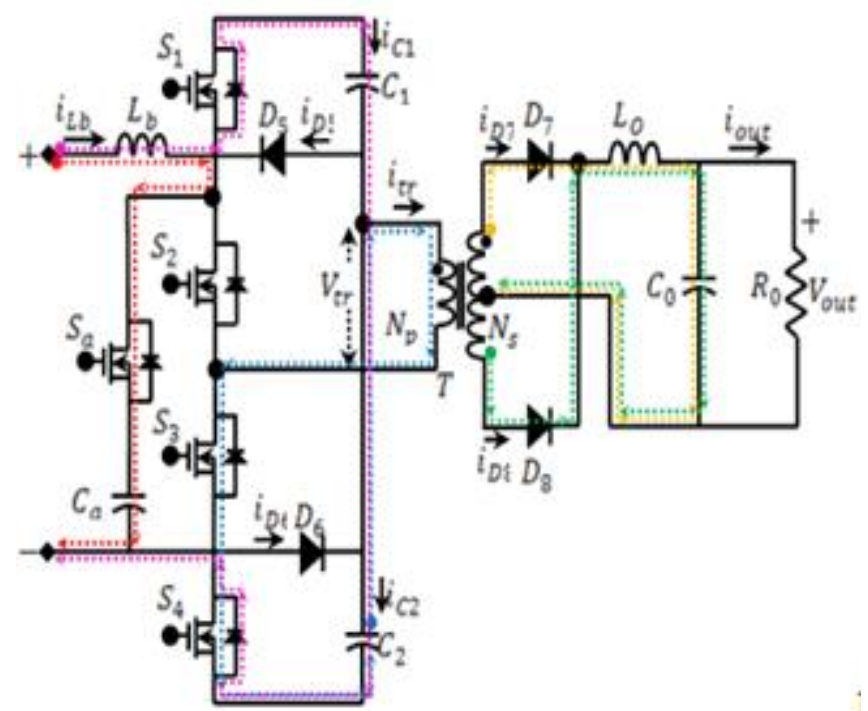

The proposed converter operating at rated supply voltage Vac (Peak) $=67.87 \mathrm{~V}$ and power on load Pout $=500 \mathrm{~W}$ and rated current Ipeak on load $=15.890 \mathrm{~A}$ it clearly shows in fig 4(d),4(c),4(e) respectively. As from the fig 4(a)-4(c), the load voltage, current, and output power is maintained as per the reference value. Here parameters like Vout, Iout, Pout indicate with a reference value and actual with respect to the various time interval, notice that output power obtained as an aspect of the proposed system.

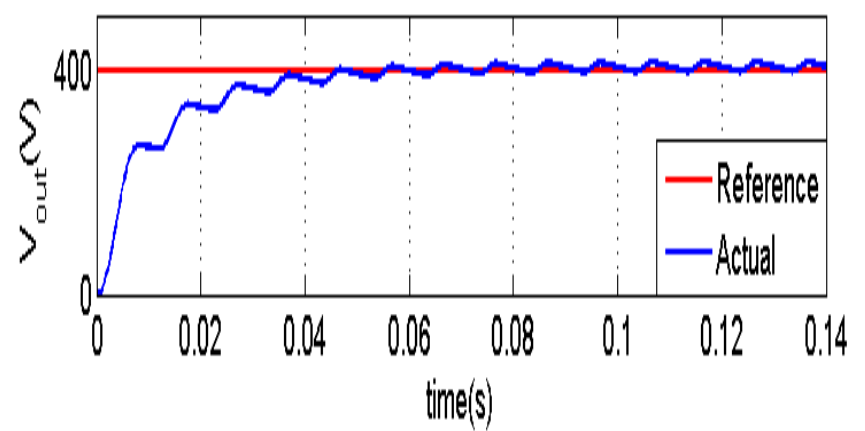

(a)

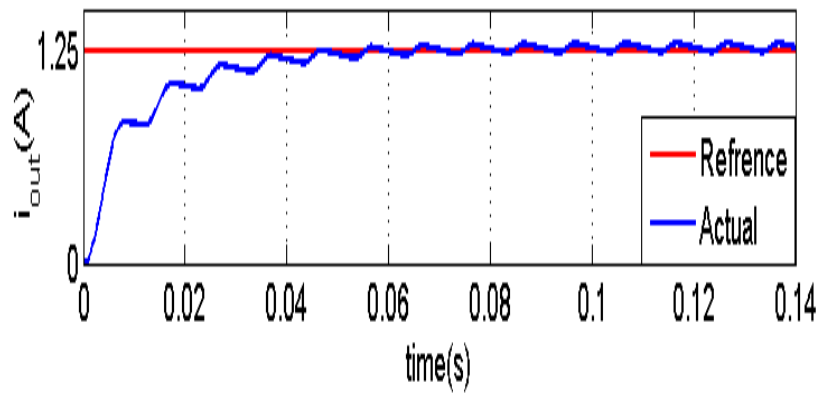

(b)

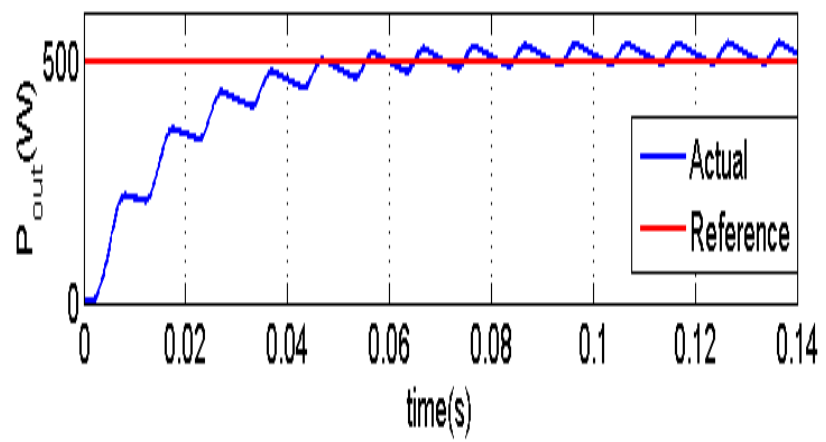

(c)

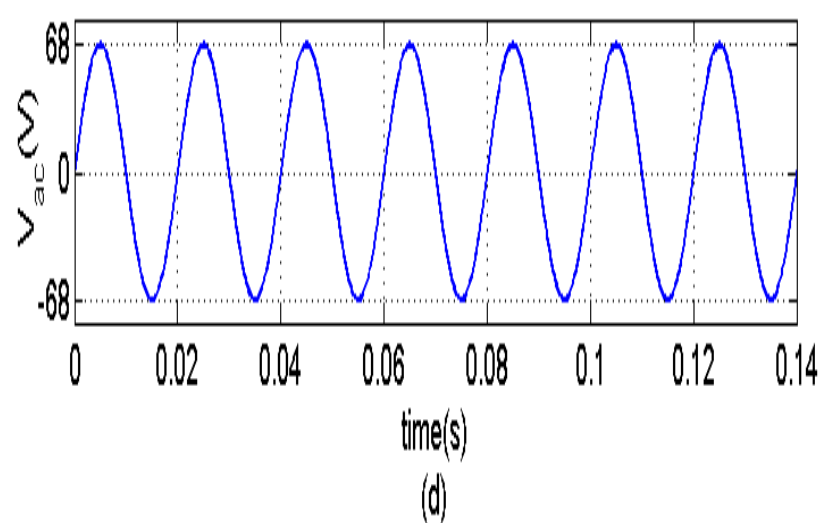

Fig. 3: (d) Equivalent circuit

A. Steady state performance 


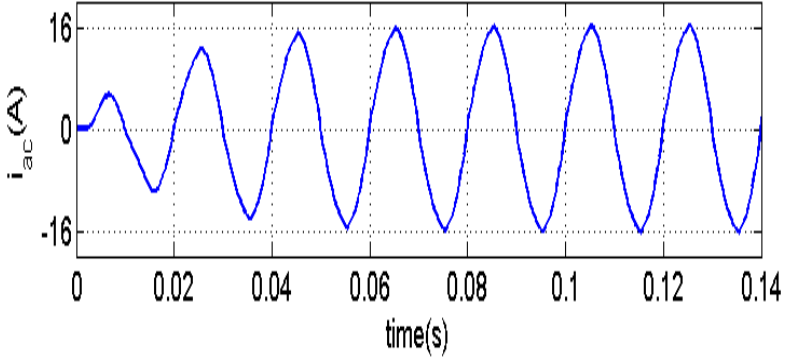

(e)

Fig. 4: Steady state performance of proposed converter (a) output voltage (b) output current (c) output power (d) supply voltage (e) supply current

\section{B. Power factor pre-regulator}

A proposed converter as power factor is an evidence for better efficiency and power factor by the various waveform. In preregulation supply current as shown in fig 5 in sinusoidal waveform voltage and current are in phase with respect to time.In fig 5 (b) capacitor $\mathrm{C} 1$ pulsating DC voltage are in phase and positive which are in phase with each other similarly for capacitor C2 voltage as in fig 5 (c). The Primary transformer (Vtr) magnitude is uniform in both positive as well as negative half cycle and also in phase with a supply voltage (Vac) as shown in Fig 5(d).Inactive and reactive power are shown to calculate efficiency an input power measured as $539.4 \mathrm{~W}$ as shown in fig 5(e), achieved better power factor which is very close to unity power factor 0.999985 that which are shown in fig 5(f). By calculating Total harmonics distortion THD using FFT analysis identified that $3.57 \%$ at a fundamental frequency $(50 \mathrm{~Hz})=15.88$ as in fig $5(\mathrm{~g})[8]$.

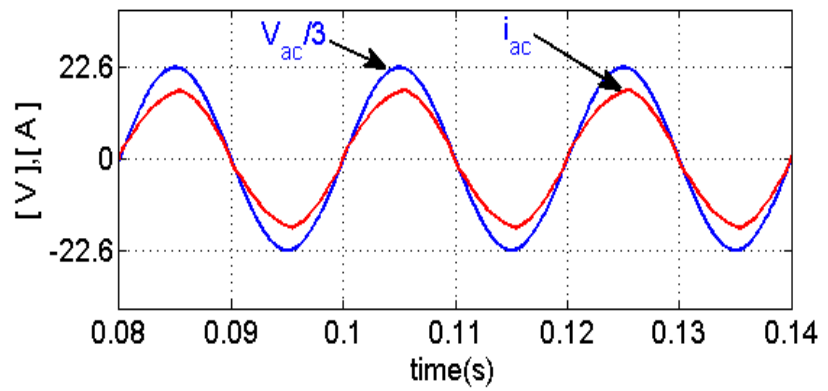

(a)

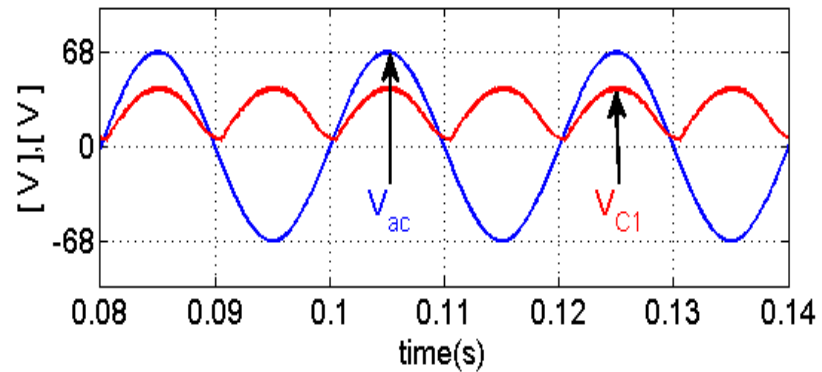

(b)

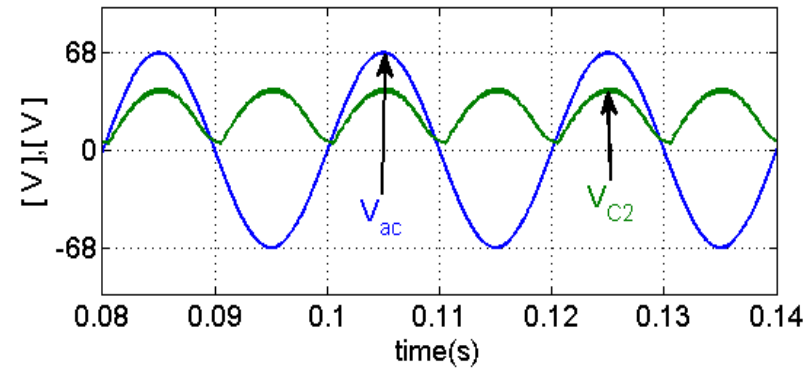

(c)

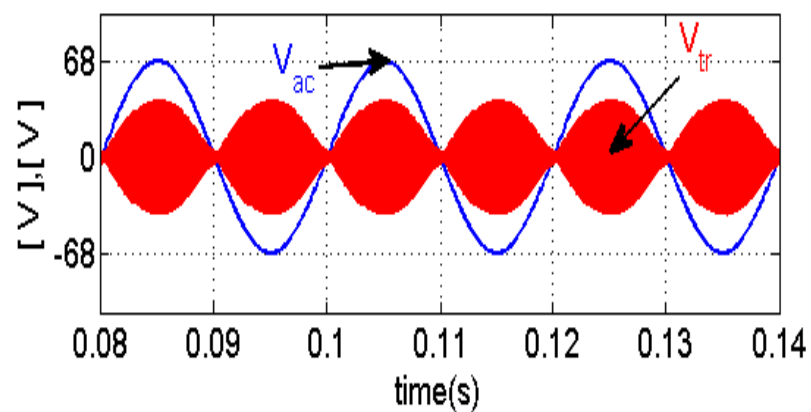

(d)

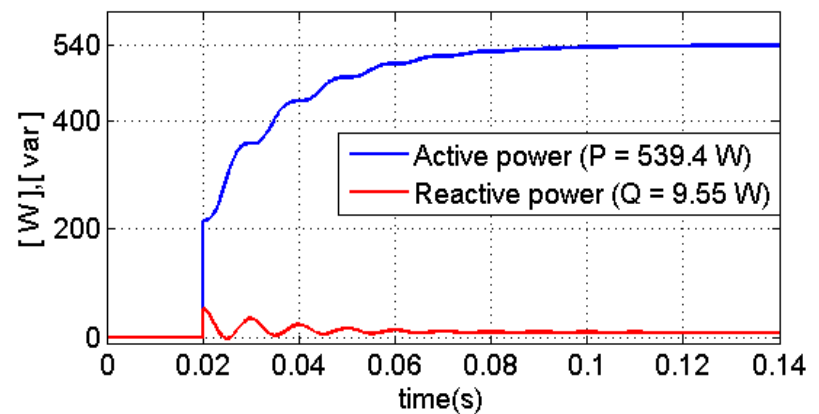

(e)

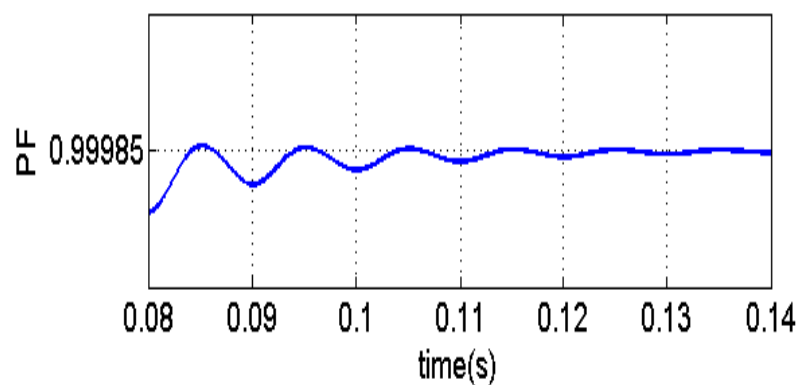

(i)

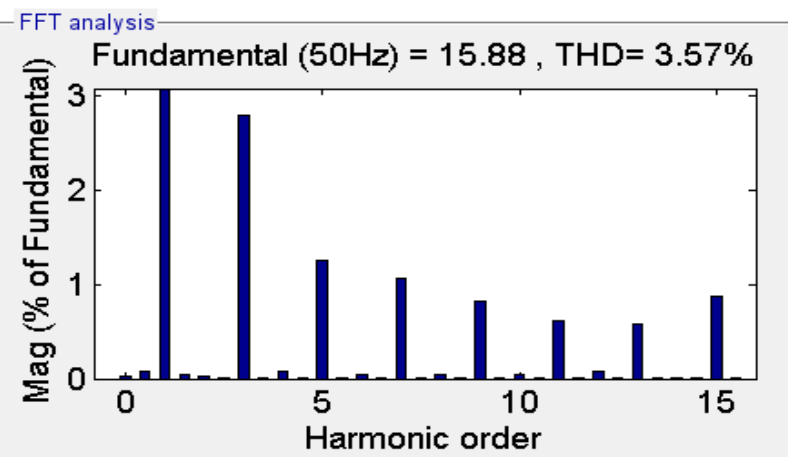

Fig. 5: Waveforms of proposed converter as power factor pre-regulator (a) supply current (b) capacitor $\mathrm{C}_{1}$ voltage (c) capacitor $\mathrm{C}_{2}$ voltage (d) transformer primary voltage with respective of supply voltage (e) active and reactive power (f) power factor (g) harmonic spectra of supply current

\section{Performance comparison}

In this proposed ZVS converter focused on S2 and S3 switches so the comparison is made between without ZVS and with ZVS. In voltage and current stress estimation of proposed converter waveform Fig 6 (a)-(b) are without ZVS for switches S2 and S3 respectively similarly Fig 6 (c)-(d) are with ZVS waveform for various specification this waveform clearly indicate power losses under switching operation of S2 and S3 are minimized under ZVS system overall power losses S2 and S3 are calculated that without ZVS power losses is $26 \mathrm{~W}$ but with ZVS power losses reduced to $16.7 \mathrm{~W}$ so $64.23 \%$ of losses are avoided by using with ZVS its help for improved life of the switches and also better efficiency, with better power factor. 


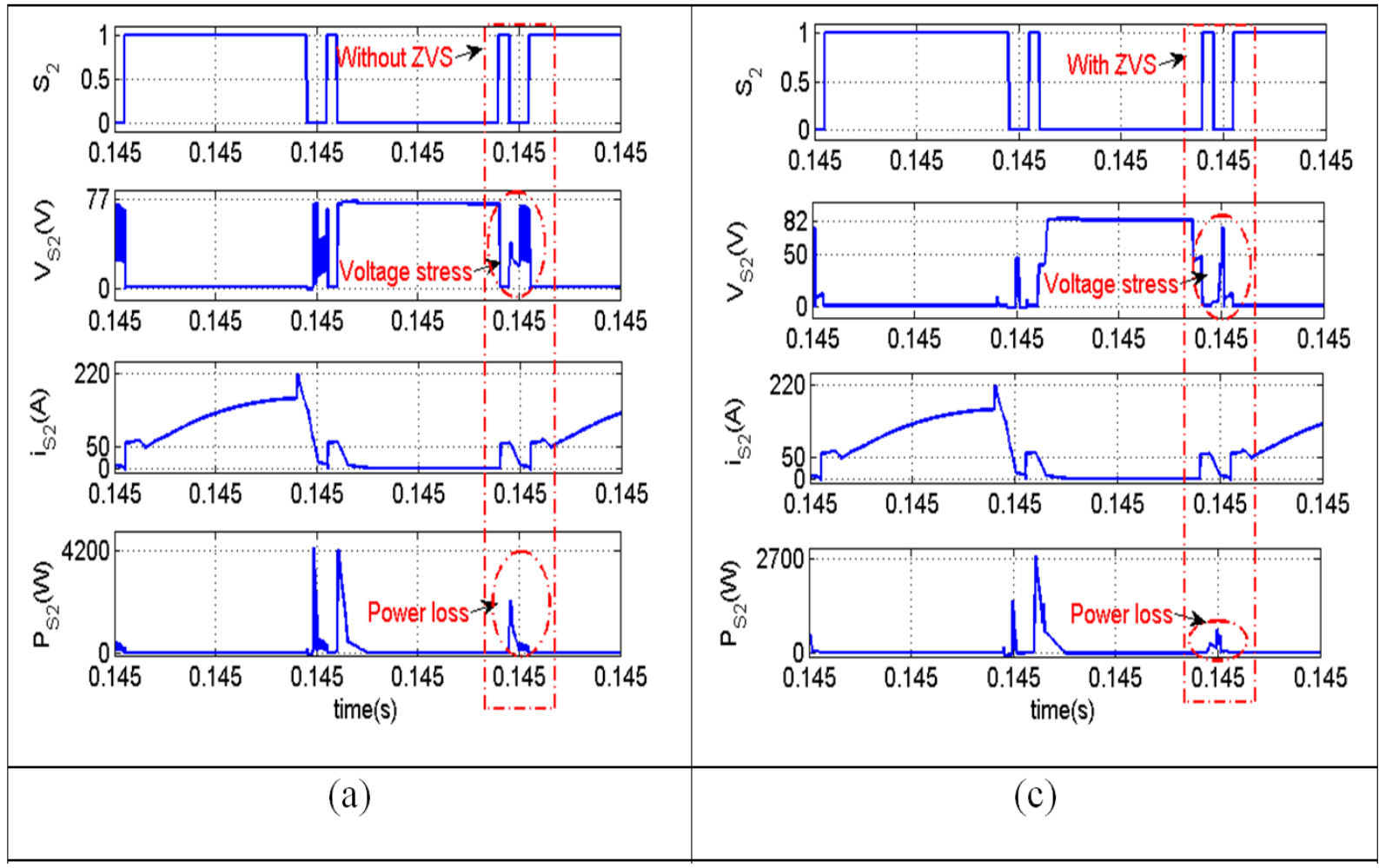

Fig. 6: (a) Voltage and current stress estimation of proposed converter switches $S_{2}$ (a) without ZVS , (b) with ZVS

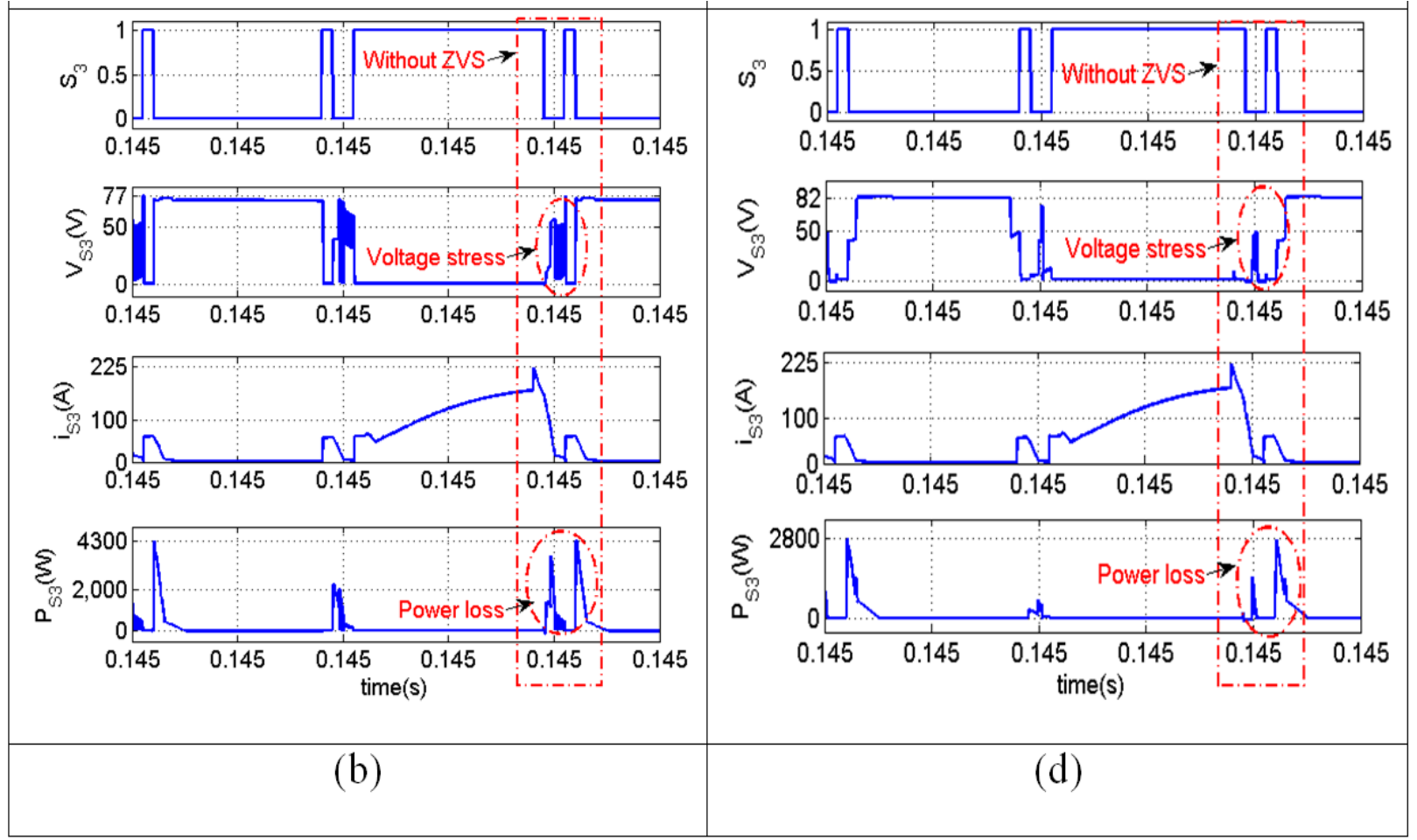

Fig.6: (b) Voltage and current stress estimation of proposed converter switches $\mathrm{S}_{3}$ (b) without ZVS, (d) with ZVS

\section{Result and Discussion}

The converter modeling in a MATLAB by the use of the sim power system. Its staging is a judge for both rated and enterprising situation. Parameters like supply voltage (Vac) in rms, supply voltage (Va) in peak, input voltage (Vin) input current (Iin) output power (Pin) and converter output like output voltage (Vout) output current (Iout) output power (Pout) switching frequency supply frequency, efficiency, power factor(PF), transformer ratio 1:12.5, of the proposed system are analyzed for exhibit its proper functioning. In addition, investigated power factor pre-regulation capacitors $\mathrm{C} 1$ voltage, $\mathrm{C} 2$ voltage, transformer primary voltage with respective supply voltage, active and reactive power, power factors and THD of spectra of supply current are evaluated for power quality at ac in main. The converter specification that is make used for the simulation are given in Table 1 
Table 1: Specification for proposed system

\begin{tabular}{|c|c|}
\hline OBJECTS & VALUES \\
\hline Supply Voltage $\mathrm{V}_{\mathrm{ac}}$ in rms & $48 \mathrm{~V}$ \\
\hline Supply Voltage $\mathrm{V}_{\mathrm{ac}}$ in peak & $67.87 \mathrm{~V}$ \\
\hline Supplu Current $\mathrm{I}_{\mathrm{ac}}$ in rms & 11.238 \\
\hline Supply Current Peak & 15.890 \\
\hline Output Voltage $\left(\mathrm{V}_{\text {out }}\right)$ & $400 \mathrm{~V}$ \\
\hline Output current $\left(\mathrm{I}_{\text {out }}\right)$ & $1.25 \mathrm{~A}$ \\
\hline Output Power( $\left.\mathrm{P}_{\text {out }}\right)$ & $500 \mathrm{~W}$ \\
\hline Input power & $539.4 \mathrm{~W}$ \\
\hline Switching Frequency & $25 \mathrm{KHz}$ \\
\hline Supply Frequency & $50 \mathrm{KHz}$ \\
\hline Transformer Ratio & $1: 12.5$ \\
\hline THD & $2.84 \%$ \\
\hline Efficiency & $92.10 \%$ \\
\hline Power factor & 0.99985 \\
\hline
\end{tabular}

\section{Conclusion}

In this paper, a three-level single -stage power factor correction ac/dc converter is proposed for high power application. The proposed converter exhibit eliminating voltage stress when operating switches of S2 and S3 by using soft switching ZVS. The resulting analysis shows that under output power $500 \mathrm{~W}$ the power the power factor near to unity 0.99985 at output voltage (Vout) $=400$ and current (Iout) $=1.25$ A. Power losses are negotiated the time of switching is $26 \mathrm{~W}$ to $16.7 \mathrm{~W}$ by using soft switching. The THD at full load has experimented at 3.57\%.On the other hand, the efficiency on full load at $48 \mathrm{~V} / 400 \mathrm{~V}$ is improved efficiency $92.10 \%$ at low input line voltage.

\section{References}

[1] A non linear controller for transformer less ac/dc converter using sepic applicable to hybrid electric vehicle," Journal of Advanced Research in Dynamical and Control Systems.vol. 09,SP-06 Pages: 291-297, Sep.2017 .

[2] A.Khaligh and S. Dusmez, "Comprehensive topological analyses of conductive and inductive charging solutions for plug-In electric vehicles," IEEE Trans. Veh. Technol., vol. 61, no. 8, pp. 3475-3489, Oct. 2012.

[3] D.D.C.Lu,H.H.C.Iu,andV.Pjevalica,"A single stage AC/DC converter with high power factor, regulated bus voltage, and output voltage," IEEE Trans. Power Electron., vol. 23, no. 1, pp. 218-228, Jan. 2008

[4] H. J. Chiu, Y. K. Lo, H. C. Lee, S. J. Cheng, Y. C. Yan, C. Y. Lin, T. H. Wang, and S. C. Mou, "A single-stage soft-switching flyback converter forpower-factor-correction applications, "IEEE Trans.Ind.Electron.,vol. 57, no. 6, pp. 2187-2190, Jun. 2011

[5] H. Ma, Y. Ji, and Y. Xu, "Design and analysis of single-stage power factor correction converter with a feedback winding," IEEE Trans. Power Electron., vol. 25, no. 6, pp. 1460-1470, Jun. 2010.

[6] H. Ribeiro and B. Borges, "High performance voltage fed ACDC full bridge single-stage PFC with reduced DC Bus capacitor," IEEE Trans. Power Electron., vol. 29, no. 6, pp. 2680-2692, Jun. 2014.

[7] H. S. Ribeiro and B. V. Borges, "New optimized full-bridge single-stage AC/DC converters," IEEE Trans. Ind. Electron., vol. 58, no. 6, pp. 2397-2409, Jun. 2011

[8] J. Everts, F. Krismer, J. V. den Keybus, J. Driesen, and J. W. Kolar, "Optimal ZVS modulation of single-phase single-stage bidirectional DAB AC- DC converters," IEEE Trans. Power Electron., vol. 29, no. 8, pp. 3954-3970, Aug. 2014.
[9] J. R. Morrison and M. G. Egan, "A new modulation strategy for a buck boost input AC/DC converter," IEEE Trans. Power Electron., vol. 16, no. 1, pp. 34-45, Jan. 2001

[10] M. Narimani and G. Moschopoulos, "A three-level integrated AC/DC converter," IEEE Trans. Power Electron., vol. 29, no. 4, pp. 1813-1820, Apr. 2014.

[11] P. Das, M. Pahlevaninezhad, and G. Moschopoulos, "Analysis and design of a New AC-DC single-stage full-bridge PWM converter with two controllers," IEEE Trans. Ind. Electron., vol. 60, no. 11, pp. 4930-4946, Dec. 2013.

[12] S. Dusmez and A. Khaligh, "A charge-nonlinear-carriercontrolled reduced-part single-stage integrated power electronics interface for automotive applications," IEEE Trans. Veh. Technol., vol. 63, no. 3, pp. 1091-1103, Mar. 2014.

[13] T.Padmapriya and V.Saminadan, "Utility based Vertical Handoff Decision Model for LTE-A networks", International Journal of Computer Science and Information Security, ISSN 1947-5500, vol.14, no.11, November 2016.

[14] S.V.Manikanthan and D.Sugandhi “Interference Alignment Techniques For Mimo Multicell Based On Relay Interference Broadcast Channel " International Journal of Emerging Technology in Computer Science \& Electronics (IJETCSE) ISSN: 0976-1353 Volume- 7 ,Issue 1 -MARCH 2014.

[15] P Bala Gopal, K Hari Kishore, B.Praveen Kittu "An FPGA Implementation of On Chip UART Testing with BIST Techniques", International Journal of Applied Engineering Research, ISSN 0973-4562, Volume 10, Number 14 , pp. 34047 34051, August 2015

[16] Arunkumar, T.S. Sivakumaran, K. Ramash Kumar, "Improved Performance of Linear Quadratic Regulator plus Fuzzy Logic Controller for Positive Output Super Lift Luo-Converter," Journal of Electrical Engineering, Vol. 16, Edition:3, 2016, pp. 397-408. 